CORRECTION OPEN

\title{
Correction to: Galectin-9 promotes a suppressive microenvironment in human cancer by enhancing STING degradation
}

Chuan-xia Zhang, Dai-jia Huang, Valentin Baloche (D), Lin Zhang, Jing-xiao Xu, Bo-wen Li, Xin-rui Zhao, Jia He, Hai-qiang Mai, Qiu-yan Chen, Xiao-shi Zhang, Pierre Busson (D), Jun Cui (D) and Jiang Li (iD)

(c) The Author(s) 2021

Oncogenesis (2022)11:5 ; https://doi.org/10.1038/s41389-021-00375-2

Correction to: Oncogenesis https://doi.org/10.1038/s41389-02000248-0, published online 06 July 2020

Following the publication of this article the authors noted errors in Figs. 2 and 5.

In Fig. 2e, the FACS plot image was duplicated by mistake.

In Fig. 5B, an additional sample was included in the lower $\beta$-actin band by mistake.

Both figures have now been corrected

The authors confirm that these errors do not affect the conclusions of the article.

The original article has been corrected.

\begin{abstract}
(i) Open Access This article is licensed under a Creative Commons Attribution 4.0 International License, which permits use, sharing, adaptation, distribution and reproduction in any medium or format, as long as you give appropriate credit to the original author(s) and the source, provide a link to the Creative Commons license, and indicate if changes were made. The images or other third party material in this article are included in the article's Creative Commons license, unless indicated otherwise in a credit line to the material. If material is not included in the article's Creative Commons license and your intended use is not permitted by statutory regulation or exceeds the permitted use, you will need to obtain permission directly from the copyright holder. To view a copy of this license, visit http://creativecommons. org/licenses/by/4.0/.
\end{abstract}

(c) The Author(s) 2021 